\title{
Building conceptions of teaching: Students' perceptions expressed through artifacts
}

\section{Moeniera Moosa}

Studies in Education Division, School of Education, University of the Witwatersrand, Johannesburg, South Africa

Moeniera.Moosa@wits.ac.za

https://orcid.org/0000-0002-6231-9370

\section{Laura Dison}

Curriculum Division, School of Education, University of the Witwatersrand, Johannesburg, South Africa Laura.Dison@wits.ac.za

https://orcid.org/0000-0002-1626-4954

(Received: 23 January 2020; accepted: 17 July 2020)

\section{Abstract}

Teacher education researchers have been grappling with the question of how students perceive teaching. This is an issue complicated by inadequate schooling conditions. In this paper, we report on an intervention used in a campus-based teaching experience programme at the Wits School of Education that involved first-year students producing artifacts that included statues or posters to depict their conceptions of teaching. Students drew on their schooling experiences to formulate their ideas. Our intention was to provide multimodal opportunities for first-year student teachers to articulate their views and perform, as it were, their understanding of teaching through visual and written forms. We wanted to explore how students, working in groups, developed the capacity to represent their conceptions as they designed and made an artifact to depict the role of South African teachers. Interesting findings about the power of representing ideas visually in combination with written reflections emerged from our analysis of their outputs. We argue that the exclusive use of traditional written methods to elicit student teachers' conceptions of teaching limits the creative and critical possibilities for students to extend and challenge their common-sense assumptions about teaching.

Keywords: academic writing, artifacts, conceptions, first year students, multimodal, perceptions, preservice teachers 


\section{Introduction and background to the artifact building project}

In this paper, we explore an artifact-building intervention in a campus-based teaching practice programme at the Wits School of Education in Johannesburg. The project began in 2015 during the period of student protests that began in opposition to a statue of Cecil John Rhodes at the University of Cape Town (UCT). ${ }^{1}$ We wanted to work with the symbols of colonisation that came to the fore for students during these protests to promote thinking about their role as teachers. We support Jansen's (2017) position on the decolonisation of the curriculum which is a commitment to interpret the curriculum to students on the basis of their own experiences, backgrounds, politics, and preferences and involves an "active engagement with entangled knowledges" (171). This project was conceptualised and implemented as a means of responding to students' concern with access to various forms of knowledge, a subject that was debated vigorously during the student protests.

South African university student performance has remained consistently poor and findings from the 2013 Council for Higher Education task team in South Africa on undergraduate curriculum study indicated that $55 \%$ of the total university intake will never graduate. Ian Scott, in an article in the Mail and Guardian (2017) on why students fail at university, identified a range of factors that affect student success in higher education. He argued that external factors like poverty and inadequate schooling cannot be overcome in the short term, but that effective educational interventions can address major obstacles to epistemic access and students' under-preparedness for tertiary study. He highlighted the significance of acquiring academic literacies for successful higher learning in the form of systemic programmes that cater for the needs of all students in the disciplines rather than add-on remedial courses for students thought to be at risk.

The move away from students having to acquire a set of generic academic skills to disciplinebased academic literacies is aligned with Ashwin et al.'s (2015, p. 29) position that "we should take into account how talking and writing are bound up in particular social contexts and draw on the available ways of communicating which are used in that context." Academic staff, who designed and implemented the campus-based teaching practice programme, drew on the Wits School of Education Writing Centre ${ }^{2}$ pedagogies to embed reflection and writing as an explicit part of the teaching programme. A lecturer from the art department provided input in a lecture that included several examples of statues and other artifacts. Students clearly benefited from this supplementary input and guidance regarding the physical, spatial, and social practices necessary for the construction of artifacts.

\footnotetext{
1 Student protests started on 09 March 2015 when students defiled the statue of Rhodes on the University of Cape Town's upper campus. Cecil John Rhodes had donated part of his estate to build the UCT campus but was a British imperialist and colonist. The Wits School of Education Writing Centre was established in 2010 to create a visible support structure to improve student writing in Education disciplines. It established a contextualised model for enhancing reading and writing practices for education students.
} 
The programme designers believed that knowledge of multimodal forms of expression would provide a generative impetus to students to represent their thoughts on their role as teachers visually and verbally and that this would provide them with ways of expressing their ideas as visual artifacts. According to Ormerod and Ivanic (2000), students bring with them their values, attitudes, and ways of working based on their experiences. They have argued that while lecturers can shape these activities, they do not exercise as much control as they do in more conventional forms of writing. Multimodal activities seem to engage students' interest and enthusiasm and allow for greater variety of approach. There is an interpersonal dimension that captures the relationship between the writer/producer and the reader of a text. The reader is invited to interact visually and cognitively with the text and the textual object involves the reader in a physical way; this requires reading and treating the text as a material object. Introducing a multimodal dimension into the intervention could be an important step towards exploring other forms of expression and towards promoting identity work. Kress (1997) argued that the materiality of texts rarely attracts conscious attention from researchers but noted that materiality is a crucial element when one is producing and/or analysing a literacy artifact.

In this paper, to provide the context for this research study, we give an account of the theoretical underpinnings of the campus-based teaching practice model used at the Wits School of Education. We then go on to describe the implementation of the artifact-building project. We explain how we analysed the artifacts in relation to students' conceptions of the role of teaching based on their interpretation of learning theories. We then go on to discuss categorisations and offer reflections on the nature and range of the diverse images and objects created by the students. With its critical perspective on teacher education, this study is framed by Bandura's (1977) Social Learning Theory.

\section{First-year student's conceptions of teaching}

First-year education students arrive at university with some idea of what teaching is based on their apprenticeship of observation according to Lortie (1975) and on their conceptions and perceptions of teaching as related to their notion of professional identity as Knowles (1992) has reminded us. Given this apprenticeship of observation or, in other words, their experience of having been taught at school, they opt to become teachers for a variety of different reasons. Often, this choice is made without a critical understanding of what teaching, as a profession, entails. One reason could be that their perception of what teaching entails is based on how the profession has been sold to them by others like parents and teachers who have their own perceptions of what being a teacher is about (Pugach, 2009; Wolhuteret al., 2012) or on students autobiographies according to Nieto (2003). Added to this could be their lived experiences of being taught from either a positive or a negative perspective. Students may have been exposed to dynamic and effective teachers and hence want to emulate their positive aspects. Alternatively, they may have been exposed to weak teaching and are passionate about ensuring that the next generation of learners does not have similar experiences and have, therefore, a personal commitment to teaching (Pugach, 2009). Views depicted in various media platforms as Pugach (2009) has noted, also have an influence on 
pre-service teachers' perceptions of teaching. Media depictions of teachers having the power to fulfil a social transformative agenda or of teachers framed as passionate, committed, and hardworking individuals who place their students' needs first influence students' notions of teaching. In summary, therefore, perceptions of teaching as a profession are often based on the discourses to which students are exposed and their own lived experiences in the classroom. These multifaceted factors shape perceptions about what constitutes the role of the teacher and make the identification of conceptions and categories of teaching a highly complex process.

\section{Teaching practice model for first-year students}

As mentioned above, first-year Education students arrive at university with some idea of what teaching is based on their apprenticeship of observation as Lortie (1975) has pointed out. Hence initial teacher education programmes are not tasked simply with filling in a tabula rasa but often have to correct students' preconceived ideas that teaching is a simple process. There are various models that are used to engage students with teaching practice in their first year. One is that first-year students do varied forms of micro teaching rather than being placed in a school context at all during their first year. Another is what is known as a sink-or-swim model in which students are placed in a school to actually teach within the first few weeks of being at university. Generally, the Wits School of Education teaching practice model has made use of a combination model in which first-year students spend an equal amount of the allocated teaching practice time on campus and in a school context. The decision to adopt this model was based on a research study done by Rusznyak and Moosa (2014) at the Wits School of Education that concluded that a campus-based model in which students remain on campus rather than being placed in a school, "offers possibilities for developing students' understanding of teaching as a complex cognitive practice" (p. S91).

\section{Theoretical framework}

This research is underpinned by Bandura's (1977) Social Learning theory. We believe that first-year students form their views about teaching through observational learning (Bandura, 1977). Students will look for models who will arouse their curiosity and motivate them to learn (Kirschner et al, 1997). Since models are, as we know, people whose behaviour can be copied and who provide a guide to appropriate behaviour, for students, their teachers at school or depictions of teachers in various forms of media act as powerful models (Bandura, 1977) that represent what it means to be a teacher. For social learning to be effective, students notice what their teachers do in various teaching situations before deciding what to retain and what to discard during the observation process. This is followed by the stage of reproduction, in which students will imitate the model (during teaching practice). Students will then experience the aspect of reinforcement of suitable teacher actions which leads to a process of being motivated to repeat these actions. In addition, students' emergence of the self, their search for a teacher identity, their relationships with others, and the role of culture throughout life also influence their understanding of their role as teachers. Clearly, there is an interdependence of these socio-cultural factors on the one hand and observational learning on 
the other. In the absence of students engaging with a theoretically sound underpinning of what it means to be a teacher we argue that much of first-year students' understanding of teaching is based on observational learning. Furthermore, ideas about teaching that are socially reinforced are more likely to recur than ideas that are not reinforced. Therefore, this research in anchored in the belief that first-year students' perceptions about the role of the teacher are governed by their experiences through social learning while at school. Since there is surprisingly little research that examines the role of observational learning in influencing first-year student conceptions of teaching, we wanted to develop a more nuanced understanding of the kinds of interpretations or misinterpretations of teaching that this cohort of student brings with them into their B.Ed. degree.

\section{The artifact -building project}

In May 2015, the campus-based project was introduced to all first-year students in lieu of observing classes in schools for three weeks. As mentioned earlier, the planning committee used material and newspaper articles and commentary from the RhodesMustFall campaign as an opportunity to develop students' capacity for critical engagement and creativity. Designing an artifact was chosen as a compulsory task that all first-year students had to complete as part of an on-campus teaching practice programme. Meaningful engagement with the role of statues was behind the choice of this task. During the campus-based teaching practice programme, students were required to design and build, in groups, an artifact or produce a visual poster. They were also required to submit an individual reflection on what they had learned about teacher identity from their personal experience at school and by working with their peers on the creative task. (See appendix 1 for specific task requirements.)

The task involving an artifact required students to participate collectively in designing an artifact that depicted their conceptions of teacher identity in South Africa. They were given guidance on how to select images and objects (see Appendix 1) and were taken through a process of thinking about an image or object that reflected their understanding of teacher identity in the new South Africa. They spent three weeks during class time formulating their ideas through conversations, in writing, and in planning and constructing an artifact that would be presented in a public space in what was to be called a gallery walk at the Wits School of Education at the end of the process. As mentioned above, in addition to the group presentation, students were required to reflect individually on what they had learned from working collaboratively with their peers in terms of both the process and the content. They were also expected to articulate whether their ideas about teacher identity had changed while they were working on the project.

Each artifact was accompanied by an individual essay from each group member in which they described the artifact in relation to the role of teachers in South African schools. Furthermore, they were required to state their reasons for choosing their artifacts. The assessment criteria stressed the importance of the essay being interesting, convincing, detailed, well justified, and logical. We derived some insights from reading these essays, but they were not analysed in depth for the purposes of this research paper. 


\section{Research design}

We conducted this research using a qualitative research design. Snape and Spencer (2003, p. 22) have argued that "qualitative research covers a broad range of approaches which are linked to different beliefs about what there is to know about the social world and how to find out about it." Following Silverman (1993) this research method allowed us to understand how first-year students use visual representations to make sense of their role as teachers. In this way, a qualitative research paradigm helped us gain greater insight into how first-year students perceive teaching as a profession given that each artifact was a presentation of the participants' independent reality as Ormston et al. (2014) have pointed out.

A total of 106 groups, with 5 to 6 members per group, completed this task. Due attention was given to the ethical considerations of voluntary participation, confidentiality, and anonymity. All first-year students were invited to give us permission to photograph their artifacts and use their individual essays as part of the data offered in this paper. In line with the points made by McMillan and Schumacher (2006), participants were purposively selected since they were first-year students who participated in the campus-based teaching practice programme. Participants were required to consent to have their group's artifact analysed as well as their individual essays and no artifacts were included in this research if any group member did not give consent. Our data source relied on photographs of the artifacts as well as an analysis of the accompanying essays from the 73 groups whose members gave consent.

In moving away from traditional models of research into students' conceptions of teaching, we were particularly interested in how students represented their conceptions of teaching through their statues. This led us to formulate our research question: How do students use visuals to represent their ideas about, and understanding of, teaching?

When we coded the artifacts, we analysed the data inductively and were guided by our social learning frame as set out by Mouton and Marais (1993).This allowed us to analyse the data without any pre-exiting notions in relation to our research question. We started the analysis by noting down all the characteristics and patterns of thinking depicted in the images that represented students' conceptions of teaching. We did this process individually before we compared our analyses so as to ensure the reliability and validity of the findings. Thereafter, we constructed the codes and categories of each of the responses which gave rise to the "patterns of meanings" that McMillan and Schumacher (2010, p. 378) have discussed. We wanted to check whether what was written in the essays held up against our initial set of categories. We used a thematic content analysis approach to interpret the content and identify themes in line with Hsieh and Shannon (2005) that best described the overarching views of students. We found that even though the individual essays presented different information, the core description of the group images remained much the same. Although similar images were chosen across categories, we could infer the category from the students' accompanying written descriptions. So, for example, when the image was of an owl, all participants in their essays mentioned that owls "symbolise wisdom" just like "teachers do." 


\section{Findings}

We identified six categories that best explained participants' conceptions of teaching. The categories were derived from the participants' choice of images and words. These categories included: teachers shape learners' lives; teachers are change agents; teachers are responsible for developing learners' cognitive abilities; teachers should embrace diversity and inclusivity; teachers are lifelong learners; and teachers develop learners' knowledge. What we found interesting was that, despite students' shift in identity from being learners to being pre-service teachers, their conceptions of teaching were still based on their observational learning experiences; they modelled their teaching on those they thought of as the experts.

\section{Teachers shape learners' lives}

This was the largest category identified and it described the ideas of 16 groups in total. These groups identified the shaping of the learners' future as a core function of teachers. Images used in this category included roads, trees, classrooms, keys, an octopus, light bulbs, motherly figures, bridges, and robots. All these images alluded to teachers as individuals who play a pivotal role in "building ... future generations." Participants stated that "teachers give birth to other professions" and that "great teachers are behind all successful men and women."

In this category, participants viewed their role as teachers to be one of preparing learners to transition into the world of work. Thus, for these groups, teachers are "like the roots and a pillar of all successful minds" with "all professions [being] in the hands of teachers." Participants in this category focused mostly on teachers having the ability to stimulate learner's development and, more specifically, their future career prospects. In selecting growth-oriented images, participants showed that they viewed teaching as the "mother of all professions" and felt that "teachers are a source of energy for learners", and are able to "take learners [from] one point to the next" so that "they can reach their goals."
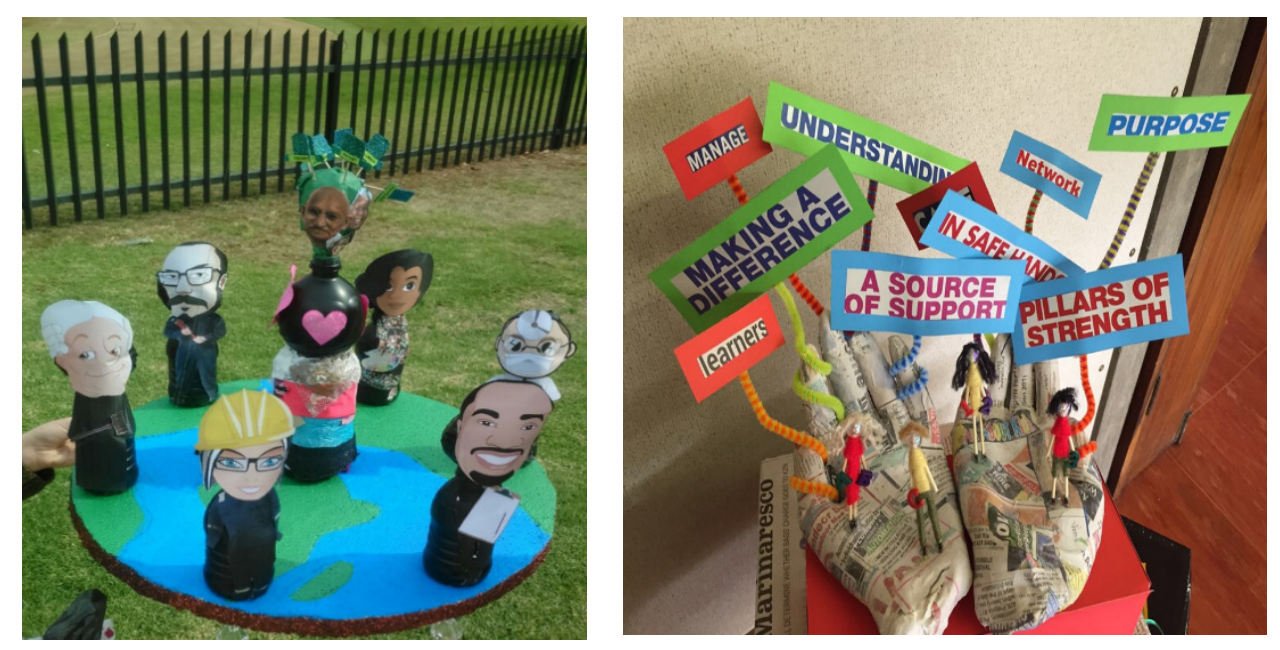

Artifacts 1 and 2: Teachers shape learners' lives 
Overall, in this category, students felt that teachers play a pivotal role in preparing, encouraging, shaping, and supporting the next generation of citizens in South Africa. This might (or might not) represent what they experienced at school as learners through their interaction with their teachers in a wide range of contexts.

\section{Teachers are change agents}

The second largest category (15 groups) identified was that of teachers promoting a transformative and social justice agenda. In this category participants viewed teachers as "agents of change" whose contribution makes a difference to society. For these groups, what teachers do has a significant impact. Images used in this category included a caterpillar transforming into a butterfly, a chicken and eggs in a nest, hands holding a globe, rain watering flowers, candles, a watering can and plants, and sailing boats.

Participants felts that "teachers change the world by transforming learners" and "build future leaders of South Africa." They indicated that teachers "in South Africa today are the faceless superhero(es) of society." The reason for this view is that "teachers carry the heavy burden of the world because only success is expected of them, hence if education fails, the nation fails." Thus, "teachers play an important role in preparing children for the real world and to acquire knowledge they will need." In this category participants felt that teachers in South Africa have an overall responsibility to bring about change in society by preparing children to contribute in a meaningful way to meet the needs of the country. Various notions of teachers' roles from their personal encounters with teachers at school most probably contributed to this fairly widespread view. The nature of this transformative potential was explored more in students' reflections on their artifacts.
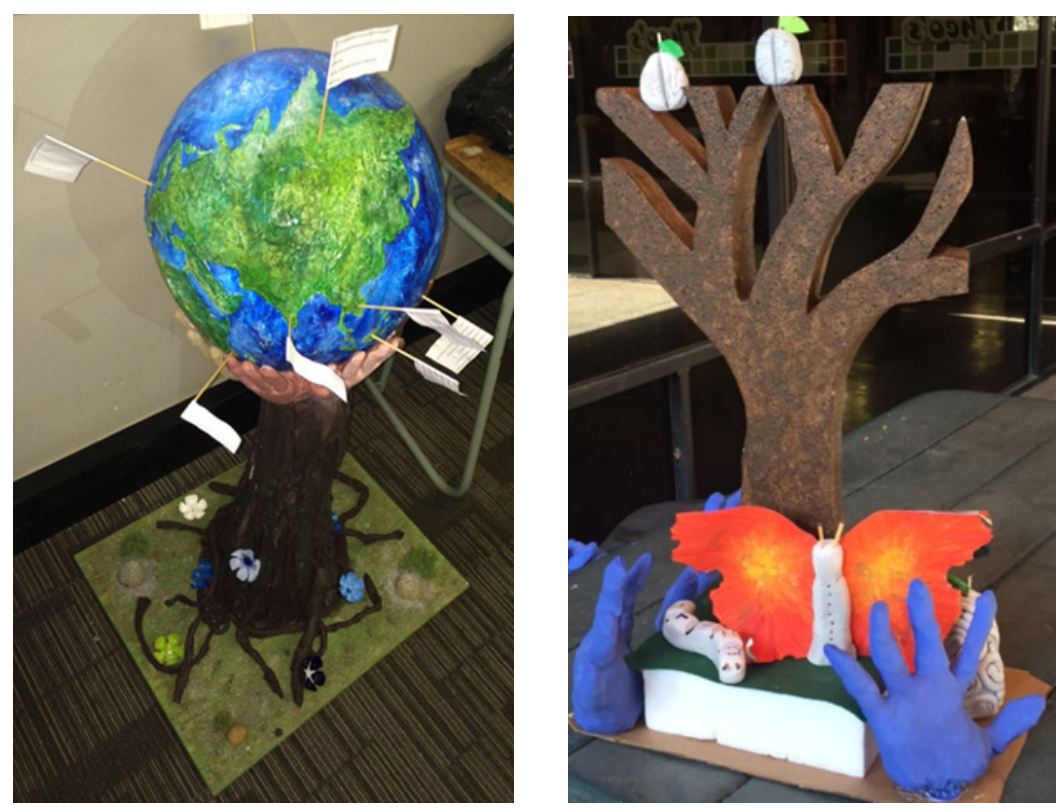

Artifacts 3 and 4: Teachers are change agents 


\section{Teachers are responsible for developing learners' cognitive abilities}

In this category, represented by 14 groups, participants placed emphasis on teachers' role in developing learners' cognitive abilities and building mental processes. Images in this category included forests, rainfalls, roads, rivers, and an owl, as well as libraries. The common ideas expressed by participants in this category were that children have "bright growing minds" and that teachers are "like farmers" and like "rain [that] nurtures and nourishes even the hardest and [most] concrete of things." Furthermore, they felt that teachers develop and expand learners' "minds" and the effect that teachers have on learners' minds lasts for a "long time" because they "help children grow." Participants also stated that "teachers create magical moments" because they are "transformers of knowledge" whose efforts "are capable of taking learners to different places." Overall, participants in this category viewed teachers as strong support bases for learners in their journey towards understanding and processing information at increasingly higher cognitive levels. It would be interesting to investigate the extent to which these particular students felt supported (or neglected) in their own cognitive journeys at school.
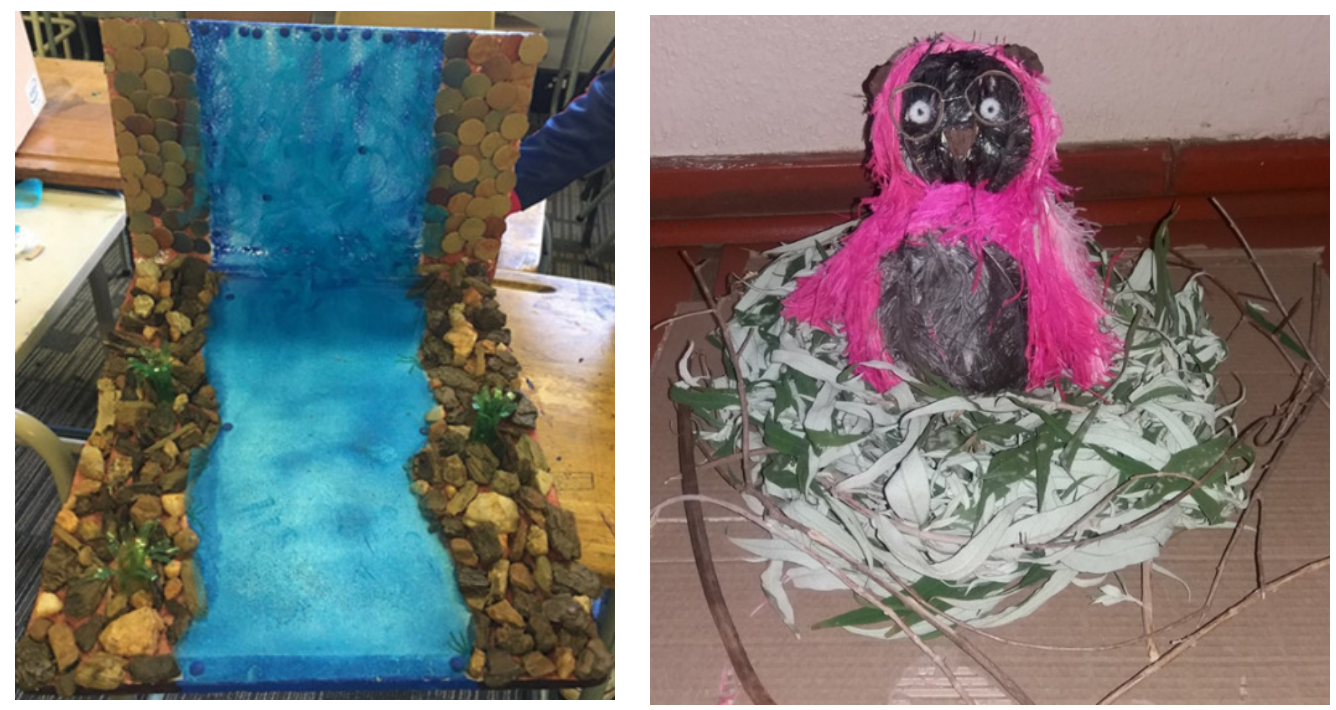

Artifacts 5 and 6: Teachers develop learners' cognitive abilities

\section{Teachers should embrace diversity and inclusivity}

The conceptions of teaching in 13 groups focused on developing the whole child who, as Merriam and Bierema (2014) have noted, includes body, mind and spirit. Participants in this category were concerned with teachers' development of potential, and their recognition of diversity and valuing of inclusivity. Images in this category included rivers, bridges, building blocks, roads, and gardens. Participants felt that "teachers see the best in their learners" and "reach out to all learners ... to help [them] overcome obstacles" and in that way "lay strong foundation and create learning opportunities for learners." Teachers in "South African schools educate children from all backgrounds, races, disabilities" and hence it is important for them to "be unbiased" in order to "educate all learners." These participants felt that "true teachers ensure that their learners are protected, they ensure that their learners go to school for a purpose, and they also ensure [that] their learners become better people after being 
taught by teachers." Teachers are able to change activities and their teaching strategies like a chameleon is able to change its colours." Overall, for this group of participants, teachers were seen as being responsible for enhancing learners' best qualities despite their backgrounds.

Through their experiences of observational learning these participants may have encountered teachers who were positive role models and because of this, wanted to be the kind of teacher who emulates this. Some students may have had teachers who were not good role models so suggested the opposite of what they had experienced at school.
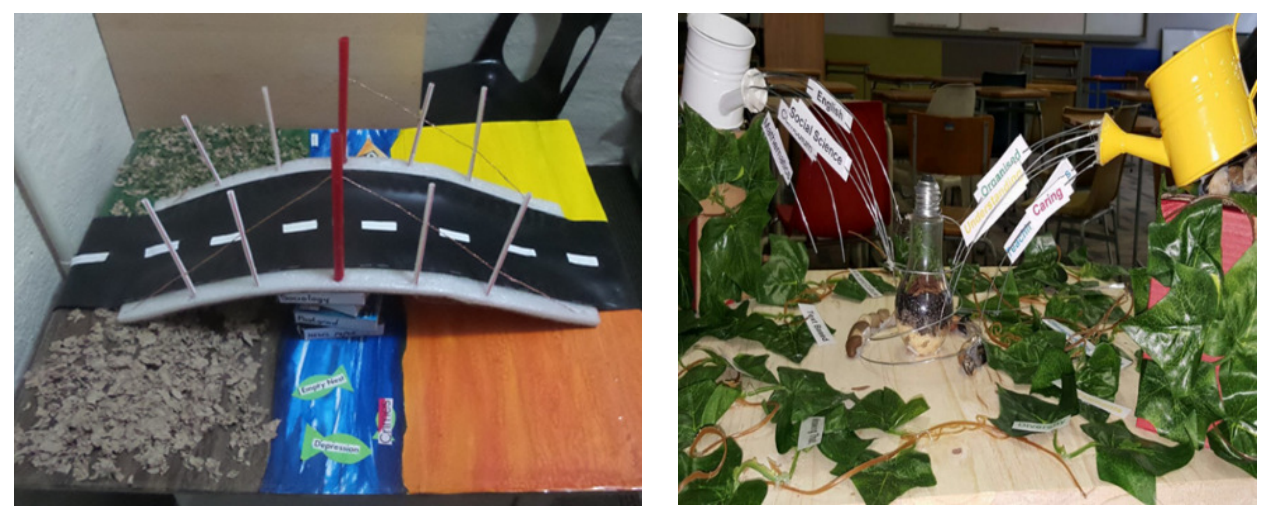

Artifacts 7 and 8: Teachers should embrace diversity and inclusivity

\section{Teachers are lifelong learners}

With regard to teacher development, six groups focused on their personal identity and professional development as teachers. They felt that teaching involves an "ever-learning process" and that teachers need to be resourceful since these are qualities that make a successful teacher. A chameleon and a teacher watering a garden were depicted in this category. One group stated that "teachers develop, evolve and grow and during that process they might shed skin and reincarnate themselves." Groups made mention of the extent to which teachers learn from their learners in meaningful ways.
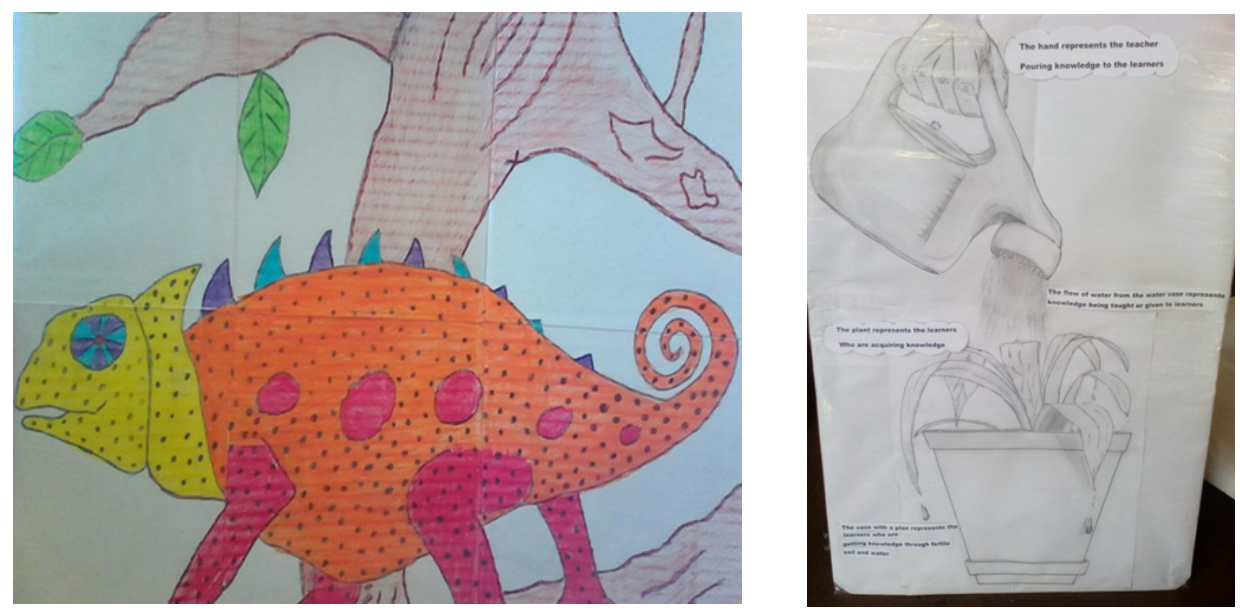

Artifacts 9 and 10: Teachers are lifelong learners 


\section{Teachers develop learners' knowledge}

Five groups viewed teaching as a profession that focuses on developing the mind with the emphasis on learners' constructing meaning and understanding for themselves with the aid and support of teachers. Participants indicated that "children grow through [the] knowledge" that teachers present to them. Teachers create meaningful understanding by allowing learners to think, reflect, and engage actively with the learning activities they create. The images used in this category included stairs, building blocks, brains, towers, and hands. Teachers of these participants may have provided them (or failed to provide them) with opportunities and processes to best understand the personal meaning the content taught had for them.

Experiencing and watching teachers perform well may have allowed them to formulate the view that teachers assist learners to reach their full academic potential through meaningful engagement with content knowledge. The opposite may, of course, have been what compelled some of these students to argue as they did.
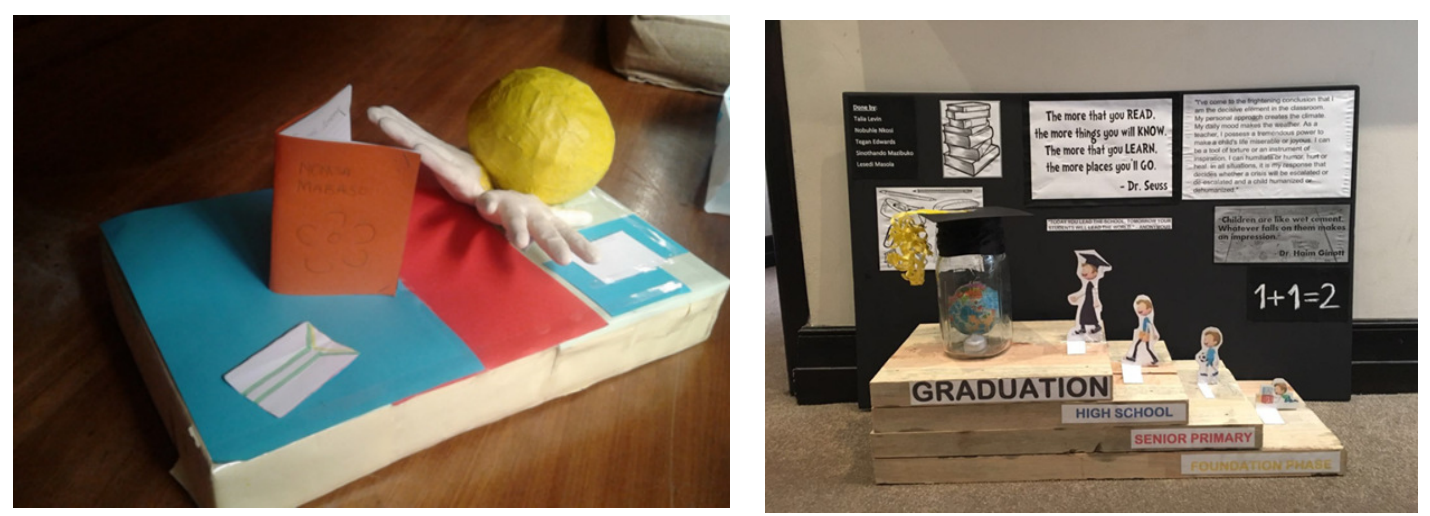

Artifacts 11 and 12: Teachers develop learners' knowledge

\section{Discussion: Affordances and constraints of the collaborative statue-building project}

Our interpretation of the students' material-based artifacts discussed above indicates the extent to which their conception of the role of teaching in South Africa is influenced by their observations of teaching. Aside from the usefulness of analysing the artifacts themselves, the collaborative process of creating each artifact gave rise to several positive spin-offs and affordances that enhanced the quality of student conversations while they produced their artifacts. First, there was evidence of substantial discussion and negotiation in the disciplinebased groups about the selection of the materials or images as well as the physical design of the artifact and how to locate all this within their surrounding social and physical environment. Second, in response to the group written task which required them to describe the object and images and provide convincing reasons for having chosen these, students engaged in conversations about these issues. This forced them to stand back from their projects to formulate explanations and justify their decisions. 
Third, students were aware that the task required them to focus on the process of working as a group and to identify their feelings and attitudes towards the artifact project as a whole. This prompted them to reflect thoughtfully on the personal and educational impact of the project.

Fourth, we argue that the opportunity for students to present their artifacts to their peers and lecturers in the gallery walk validated students' interest and increased their motivation to communicate their ideas since they felt that their modes of expression were being acknowledged and valued. The interaction between presenters and audience at the gallery walk encouraged active listening and an exchange of ideas not often experienced by first-year students. The audience members were involved in the outputs and seemed genuinely interested in understanding the rationale for the design and presentation of each artifact.

This campus-based project allowed the course designers to reflect on strategies for maximising the value of these student-created objects as visual, material, and verbal representations. Although reflection and self-reflexivity are regarded as important competences required for teaching practitioners and for critical academic engagement, there is some concern that students have not developed such capacity at school or in their university studies. A project like this would, therefore, present an ideal opportunity to introduce first-year students to these practices through sustained reflective activities and then inculcate them gradually. Some students commented on their peers' conceptions of teaching but were unable to substantiate these claims with convincing and critical evidence. For example, some students felt that images of apples, trees, roads and bridges were fairly clichéd, but they could not articulate why these were part of a naïve depiction of teachers. A detailed analysis of the students' reflections will be offered in a later paper, but a preliminary analysis of their reflections reveals a fairly formulaic and limited account of their perceptions of the value of the group process and the learning outcomes. The calibre of their outputs and capacity to self-evaluate would be similarly enhanced if feedback were provided on the objects themselves as well as on students' reflections as Boud and Molloy (2013) have suggested.

We support Huang and Archer's (2017) contention that students are faced increasingly with assignments that require the use of multimodal resources for communicating. They suggest that "student-produced texts need to integrate different semiotic resources according to different principles of organization and even written assignments [need to] take design and layout into consideration" (p. 81). Since there is ongoing pressure to find innovative ways of enhancing students' understanding of particular topics, especially in online and hybrid modes of teaching, visual representations like posters or mind maps could become key assessment strategies in professional teaching programmes.

\section{Limitations}

A limitation of this study is that it was done with one cohort of first- year students at a particular university which implies that the findings will not necessarily be transferable to all 
initial teacher education contexts. Nonetheless these findings do provide a useful basis for further research on the use of multimodal learning opportunities for university students.

On reflection, as the project designers, we are keen to re-implement the statue project as part of the campus-based programme but would integrate "learning-oriented assessment principles and practices" (Carless, 2015, p. 27) into the intervention. For example, the collaborative processes need to be better scaffolded and structured as does students' engagement with the assessment criteria when they assess each other's participation and artifacts through the application of negotiated rubrics. This would address the possible shortcoming of students' inadequate skills in observing and evaluating teaching practices that have transformative potential. We need to address the fact that students require more input on reflective writing strategies to avoid the mostly formulaic and generalised commentary that emerged as they viewed the artifacts created during this project.

Furthermore, we need to select the groups more carefully so that there is a balance of skill since this will allow us, as the designers, to recognise the observational strengths students bring from their previous experiences to the creative process and point more directly to the importance of social learning.

\section{Conclusion}

We have showcased how the campus-based statue intervention was conducted and we have shown the potential of creating and implementing multimodal experiences that cater to diverse groups of first-year students. The use of artifacts as a form of expression encouraged participatory learning and critical thinking as well as students' creative and reflective practices with regard to their understanding of the role of South African teachers. Although this project took place a few years ago, students who participated in it have remarked on its having been a turning point in challenging some of their assumptions about their identities as teachers and about the collaborative process itself. They commented positively as did education lecturers on the current value of these striking and thought-provoking representations of teaching in a context of tension and flux.

We argue that we lack a theory of what it means to be a teacher and that that many first-year students' understanding of teaching is based on observational learning. The importance of social learning and observational learning in pre-service teacher's conceptualisation of teaching cannot be underestimated but should be explicitly integrated into the curricula as an object of learning in first year B. Ed courses. Social learning in the context of the statue project is intended to provide a framework for thinking about the value of learning in communities of practice in our relationships, our communities, and our organizations as advocated by Wenger (2018). This campus-based statue project is a vivid example of how social learning can be embedded in a teacher development programme. It could serve the dual purpose of modelling an innovative experience for student teachers of working collaboratively with their peers on a project and deepening their conceptions of teaching experientially and conceptually. 


\section{References}

Ashwin, P., Boud, D., Coate, K., Hallett, F., Keane, E., Krause, K., Leibowitz, B., MacLaren, I., McArthur, J., McCune, V., \& Tooher, M. (2015). In A. Pollard \& A. Pollard (Eds.), Reflective teaching in higher education (pp. 21-40). Bloomsbury.

Bandura, A. (1977). Social learning theory. Prentice-Hall.

Boud, D., \& Molloy, E. (2013). What is the problem with feedback? In D. Boud \& E. Molloy (Eds.), Feedback in higher and professional education: Understanding it and doing it well (pp. 1-10). https://doi.org/10.4324/9780203074336

Carless, D. (2015). Excellence in university assessment: Learning from award-winning practice. Routledge. https://doi.org/10.4324/9781315740621

Hsieh, H. F., \& Shannon, S. E. (2005). Three approaches to qualitative content analysis. Qualitative Health Research, 15(9) 1277-1288.

Huang, C., \& Archer, A. (2017). Training writing centre tutors for argument in a digital age. In S. Clarence \& L. Dison (Eds.), Writing centres in higher education: Working in and across the disciplines (pp. 81-96). Sun Press.

Jansen, J. (2017). As by fire: The end of the South African university. Tafelberg.

Kirschner, P., Van Vilsteren, P., Hummel, H., \& Wigman, M. (1997). The design of a study environment for acquiring academic and professional competence. Studies in Higher Education, 22(2), 151-171.

Knowles, J. G. (1992). Models for understanding pre-service and beginning teachers' biographies: Illustrations from case studies. In I. F. Goodson (Ed.), Studying teachers' lives (pp. 99-152). Teachers College Press.

Kress, G. (1997). Before writing: Rethinking the paths to literacy (1st ed.). Routledge. https://doi.org/10.4324/9780203992692

Lea, M. R., \& Street, B. V. (1998). Student writing in higher education: An academic literacies approach. Studies in Higher Education, 23(2), 157-172. https://doi.org/10.1080/03075079812331380364

Lortie, D. C. (1975). Schoolteacher: A sociological study. The University of Chicago Press.

McMillan, J. H., \& Schumacher, S. (2010). Research in Education: Evidence-based enquiry. Pearson Education.

Merriam, S. B., \& Bierema, L. L. (2014). Adult learning: Linking theory and practice. Jossey Bass. 
Mouton, J., \& Marais, H. C. (1993). Basic concepts in the methodology of the social sciences. Human Sciences Research Council.

Nieto, S. (2003). What keeps teachers going? Teachers College Press.

Ormerod, F., \& Ivanic, R. (2000). Texts in practices: Interpreting the physical characteristics of children's project work. In D. Barton, M. Hamilton \& R. Ivanic (Eds.), Situated literacies: Reading and writing in context (pp. 91-107). Routledge.

Ormston, R., Spencer, L., Barnard, M., \& Snape, D. (2014). The foundations of qualitative research. In J. Ritchie, J. Lewis, C. M. Nicholls, \& R. Ormston (Eds.), Qualitative research practice: A guide for social science students and researchers (pp. 1-27). SAGE.

Pugach, M. C. (2009). Because teaching matters: An introduction to the profession (2nd ed.). John Wiley \& Sons, Inc.

Rusznyak, L., \& Moosa, M. (2014). Supporting student teachers through their first attempts at teaching: Possibilities and limitations afforded by school-based and campus-based models of support. Education as Change, 18(sup.1), S91-S105.

https://doi.org/10.1080/16823206.2013.877354

Scott, I. (2017). Core issues besides finance and access hinder students' success. Mail and Guardian, 20 October. https://mg.co.za/article/2017-10-20-00-core-issues-besidesfinance-and-access-hinder-students-success/

Silverman, D. (1993). “Beginning Research.” Interpreting qualitative data. Methods for analysing talk, text and interaction. SAGE.

Snape, D., \& Spencer, L. (2003). No Title. In J. Ritchie \& J. Lewis (Eds.), Qualitative research practice: A guide for social science students and researchers (pp. 1-23). SAGE.

Wenger, E. (2018). A social theory of learning. In K. Illeris (Ed.), Contemporary theories of learning: Learning theorists. . . in their own words (2nd ed.) (pp. 209-218). Routlege. https://doi.org/10.4324/9781315147277

Wolhuter, C., van der Walt, H., Potgieter, F., Meyer, L., \& Mamiala, T. (2012). What inspires South African student teachers for their future profession? South African Journal of Education, 32(2), 178-190. https://doi.org/10.15700/saje.v32n2a570 


\section{Appendix 1: Campus based programme artifact task}

In groups of 5-6 in tutorials, you will need to do the following:

Think about an image or object that reflects your understanding of teacher identity in the new South Africa. The image will be presented in an artifact that will be placed at the Wits School of Education (WSoE) to represent teachers.

You need to do one of the following:

1. DESIGN A POSTER THAT CAPTURES THE IDEAL CHARACTERISTICS OF A TEACHER IN SOUTH AFRICA TODAY.

Your poster needs to contain the following:

A visual representation of the artifact you have chosen

$\checkmark$ You can draw this, cut it out of magazines (provided) or stick on recyclable items.

$\checkmark$ You can create a collage of pictures, words and recyclable items.

The focus is visual representation so use words sparingly.

You also need to write on an A4 sheet:

- A description of the object - its physical and other features. If it is a historical object you need to explain its origins. (one paragraph)

- Reasons why you chose or created this particular object or image. You need to provide convincing reasons for this. (1-2 paragraphs)

- Reflect on how you worked as a group and how the artifact made you feel.

OR

1. CREATE AN ARTIFACT THAT REPRESENTS THE CHARACTERISTICS OF A TEACHER IN SOUTH AFRICA TODAY.

$\checkmark$ The artifact needs to be made from waste or recyclable materials and objects such as newspapers, sticks, stones and wire. Consider the imagery and how you will construct the artifact.

$\checkmark$ Remember artifacts are three dimensional and free standing.

Things to consider:

- Materials * Relationships

- How to join the materials

- Where will the artifact be placed?

- How will it stand? 
You also need to write on an A4 sheet:

- A description of the object - its physical and other features. If it is a historical object you need to explain its origins. (one paragraph)

- Reasons why you chose or created this particular object or image. You need to provide convincing reasons for this. (1-2 paragraphs)

- Reflect on how you worked as a group and how the artifact made you feel.

Planning checklist:

\begin{tabular}{|l|l|l|l|}
\hline $\begin{array}{l}\text { How to choose the } \\
\text { idea/ image for the } \\
\text { artifact. }\end{array}$ & $\begin{array}{l}\text { How to plan the } \\
\text { design of the } \\
\text { artifact. }\end{array}$ & $\begin{array}{l}\text { How to construct } \\
\text { the artifact, e.g. } \\
\text { what materials, } \\
\text { pictures etc. to } \\
\text { use }\end{array}$ & $\begin{array}{l}\text { How to divide up } \\
\text { tasks, e.g. }\end{array}$ \\
\hline & & & \\
\hline
\end{tabular}

2. Descriptive paragraph

- Does your paragraph begin with a description that identifies the object or image you are about to describe and suggests its significance?

- Are your descriptions clear and specific? e.g. what colour, shape, texture, size/ dimensions or connection between the parts?

- Have you put your descriptions into complete sentences?

- Is your paragraph unified--that is, do all of the supporting sentences relate directly to the topic introduced in the first sentence?

- Have you followed a logical pattern in organizing the sentences in your paragraph?

- Have you concluded the paragraph with a sentence reminding the reader of the item's special significance?

\section{Providing sound reasons}

Are your reasons for choosing the object or image:-

- Convincing

- Clearly explained

- Justified (with evidence)

- Elaborated (contain enough detail)

- Interesting 